\title{
THE PERCEPTION OF POST-PARTUM WOMEN WITH HIV / AIDS ABOUT PSYCHOSOCIAL SUPPORT IN BANDUNG CITY
}

\author{
Nunung Nurhayati ${ }^{1}$, Lia Juniarni ${ }^{2}$, Mimin Sumiati ${ }^{3}$ \\ ${ }^{1}$ STIKEP PPNI Jawa Barat-RSUP DR Hasan Sadikin Bandung \\ Correspondance: juniarnilia@yahoo.com
}

\begin{abstract}
About 17 million women around the world aged 15-49 years are infected with HIV and AIDS. HIV / AIDS is transmitted from mother to baby during pregnancy, intra-natal, postnatal and it is a cause of death. In 2015, HIV transmission occurred in more than 38,500 children born to HIVpositive women. Transmission of HIV / AIDS from mother to baby during labor can be prevented by ARV therapy. The psychological aspects of postpartum women with HIV / AIDS include fear, shame, and a higher risk of depression compared to normal postpartum. Social support is needed by individuals in the situation. The participants in this study were 6 people. The sampling technique used purposive sampling with the inclusion criteria for post-partum women with HIV / AIDS who routinely controlled treatment. The results of the study found the theme of psychosocial support from the closest person consisted of 3 categories, namely psychological support from the family, support from fellow friends with HIV / AIDS and support in undergoing treatment. Conclusions from the results of the study found new insights that post-partum women with HIV / AIDS had accumulated feeling from the process of HIV / AIDS. Support is needed from the people closest to the family and support from fellow friends with HIV / AIDS, to prevent continuing into the desperation stage that results in death.
\end{abstract}

Keywords: HIV / AIDS, Physiological support, Perception, postpartum-women.

\section{INTRODUCTION}

According to the UN, about 17 million women around the world aged 15-49 years are infected with HIV and AIDS (UNAIDS, 2010), HIV / AIDS is transmitted from one mother to baby during pregnancy, intra-natal, postnatal (lactation process) and is the main cause of death in Sub-Saharan Africa. Most HIV / AIDS transmission from mothers to their babies during labor can be prevented by ARV therapy during perinatal periods. In 2010 in East Asia, South Asia and Southeast Asia around $30 \%$ of pregnant women had tested for HIV, indicating an increase compared to 2009 of around 18\% (WHO, 2011).

The AIDS cases in 2005 according to data from the Indonesian Ministry of Health based on sex was $80 \%$ in men and $19.5 \%$ in women. The highest 
presentation of HIV cases at the age of 25-49 was 73.7\% (Directorate General of P2PL of the Indonesian Ministry of Health, 2011). In 2015, there was a cumulative transmission of HIV from mothers to children of more than 38,500 children. This situation shows that HIV and AIDS must be a major concern of the Indonesian government and become a major threat if it is not balanced with the prevention and treatment efforts (IPPI Research Final Report, 2010).

A feeling of high concern for postpartum women with HIV / AIDS is related to concerns about transmitting HIV / AIDS infection to their babies, feeling depressed and feeling not the same as other postpartum women. Researchers in September 2012 interviewed one of the postpartum women with HIV / AIDS saying, "I have this disease transmitted from my second husband, my husband's job was a truck driver, I did not know my husband was HIV positive, my husband died after one year of marriage, now I have a third husband, and have children, hopefully my child is not infected, Alhamdulillah my husband accepts that I am HIV positive, sometimes when having sexual intercourse my husband did not use condoms, I reminded him but he was not willing to, I am sad and disappointed to have a disease this, I once thought of committing suicide but I remembered the children".

The psychological aspects of postpartum women with HIV / AIDS include fear, shame which resulted in a higher risk of depression compared to normal post-partum and resulted in a desire to commit suicide. Social support is needed by an individual in this situation. Social support is access to an individual, groups or institutions that can provide assistance during difficult situations (Norbeck, et.al, 1983 in Carvehaels, benicio, and Barros, 2005). 


\section{METHODS}

The design used in this study was qualitative research with a phenomenological approach that described the perception of post-partum women with HIV / AIDS about psychosocial support in the city of Bandung. The research process consisted of 4 stages: Bracketting was the participant asking something related to his illness, the researcher answered after the interview was finished, Intuiting listened carefully without giving any inquiries or suggestions, Analizing was reading descriptions of participants' experiences repeatedly until they found categories, , and theme, the final stage was describing which was compiling all data that has been grouped in the form of narration.

The participants in this study were 6 people. The sampling technique used were purposive sampling with the inclusion criteria for post-partum women with HIV / AIDS who routinely controlled treatment to the Teratai Polyclinic of RSUP Rr Hasan Sadikin Bandung. Data analysis using the Giorgi method began with reading the entire description of the experience to get a sense of the whole, reread the description, identify the transition units of the experience, clarify and elaborate the meaning by relating constituents to each other and to the whole, reflect on the constituents in the concrete language of the language of the participant, transform concrete language into the language or concepts of science, integrate and synthesize the insight into a descriptive structure of the meaning of the experience.

\section{RESULTS}


Data collection was conducted by in-depth interviews to the six participants, questions were related to the description of post-partum women with HIV / AIDS perceptions about psychosocial support. Interviews were conducted in a comfortable situation and the researcher tried not to influence the answers of the participants. Basically, the results of the interviews conducted were in accordance with the objectives of the study.

Data analysis was carried out in several stages, the first stage was listening to the interview results carefully then writing verbatim transcripts from all participants, the second stage was repetitive reading of the verbatim transcripts that had been written, the third stage was listening repeatedly to the interview record, the fourth stage was marking the participant's significant questions and analyzing those significant questions. The fifth stage was analyzing the categories to create themes, and the sixth stage was consulting with qualitative research experts about themes that have been made.

Themes found were psychosocial support from the family, support from fellow friends with HIV / AIDS and support during carrying out treatment. The theme of psychosocial support from the closest person consists of 3 categories, namely psychological support from the family, support from fellow friends with HIV / AIDS and support in undergoing treatment.

\section{Psychological support from the family}

Post-partum women who gave birth with HIV / AIDS were under pressure due to multiple stressors, namely chronic disease conditions and bad stigma from the community. Post-partum women with HIV / AIDS needed psychological support from the family. Participants 1,2, 4 and 5 revealed they really need 
psychological support in order to get back up and increased their self-confidence. Here are some statements relating to social support:

"... parents-in-law ... called ... reminded me to take medication and eat on time, avoid not eating ..., don't think about it ... everything will be healthy ... well ... encourage me to continue life ... didn't give up taking medicine ... because I have children ... while my husband died at that time ... the child was with me ..., yes, who made me not gave up was parents-in-law and children... (1.17)

Just like participant 1 , participant 2 revealed the same thing that she received psychological support from the closest family, namely from mother who gave her a spirit for not overthinking. The following was participant statement 2:

"... and mom really supported ..., when I was quite ..., excited ..., do not daydream ..., if you were excited ..., the disease would not dare to come ... (2.13)

In participant 4 revealed the same thing that family support consisted of accompanying health control, participant 4 statement:

"... my parents gave me direct support ..., if I controlled to the Teratai ..., my parents came along ..., talked to the doctor ..., there is someone who supported $\ldots(4.6)$

While for participants 5, family support that he got from his sister in the form of support for not over thinking, here is an expression from participants 5:

"... my sister said, it's okay, don't over think and don't think about it... the important thing is to get well ... (5.6)

\section{Support from fellow friends with HIV / AIDS}

In addition to getting psychological support from the family, individuals also received psychosocial support from fellow HIV/AIDS friends. The form of 
support obtained by participants was to see that they are not the only one infected with HIV / AIDS, many others were infected as well. Psychosocial support from fellow HIV / AIDS friends was revealed by participants 2 and 4 .

"... I am comforted when I control to the Teratai ..., when I met a sufferer, I got up again ... I realized it turns out that I am not the only one ... I felt a little bit calm ... (2.8)

The same thing was expressed by participant 4 , the following was the expression from participant 4 :

"... when I am home, I am the only one infected..., but when you go to the Teratai, you realize that there are also many who are infected with HIV ... when I controlled to the Teratai I'd like to have a chat with others... there is one whose house is near my parents-in-law... there is my neighbor who is also infected ..., who often go to the Teratai clinic ..., sometimes we would like to have a chat there ..., so it's like having a new world ..., new friends who understand each other ... (4.23))

\section{Support in undergoing treatment}

Two participants expressed psychological support from the family towards postpartum individuals with HIV / AIDS in undergoing treatment, experienced by participants 5 and 6 . Following are some statements by individuals as follows:

"... my sister said it's okay ..., the important thing is that we only get routine treatment ..., don't give up ... (5.5)

The same was expressed by participant 6 , who revealed that he had to take medication regularly, following a statement from participants 6: 
"... my brothers and sisters give me encouragement ... you don't have to overthink right now ..., you have to eat ..., take medicine regularly ... (6.2)

\section{DISCUSSION}

The results of this study indicate the need for psychosocial support from family and peer friends with HIV / AIDS for individuals with HIV / AIDS. Participants after giving birth with HIV / AIDS in this study received support both internally and externally. Internally obtained from family members such as husband, brother, sister, grandmother, parents-in-law, and mother, while externally obtained from fellow friends with HIV / AIDS. Existing support systems are the factors that strengthen postpartum participants to overcome HIV / AIDS. Some participants revealed that they desperately need support, so they could rise back up and improved their confidence. All participants revealed that family support was very important and meaningful to achieve well condition. Some participants revealed that they needed the support of close friends with HIV / AIDS. Postpartum participants with HIV / AIDS are under pressure due to multiple stressors, namely disease conditions and bad stigma from community diseases.

Psychosocial support is access to an individual, groups or institutions that provide assistance in difficult situations (Norbeck, et.al, 1983 in Carvehaels, benicio, and Barros, 2005). Pender (2001) defined psychosocial support as a feeling of belonging, feeling accepted, valued, appreciated, needed by others, not just what someone did for others. Person (2009) stated that positive family support influenced coping and the individual's ability to develop realistic coping in overcoming pressure. Positive support for post-partum women with HIV / AIDS helped them deal with their problems. According to Ryan and Austin (in 
Friedman, 2004) that adequate support is related to mortality, and accelerated healing. According to Wagner (2009) that emotional support referred more to give enthusiasm, warmth, and love. Besides the emotional support of participants, they also get support in the form of material or financial. This form of support reduces stress because an individual could directly solve problems that are related to money (Ameneh et al, 2013). This was corresponding with research conducted by Close (2010), individuals with HIV / AIDS fear the stigma of the community more than they fear death caused by the disease, individuals with HIV / AIDS tend to seek psychosocial support for fear of rejection or social isolation. Individuals with HIV / AIDS who are in a state of despair needed supports in order to rise again (Wagner, 2009). Family involvement is very important to reduce the stigma felt by individuals with HIV / AIDS because families understand the emotional state of the patient the most, understand the needs and provide comfort (Laura Nyblade, 2009). Sometimes family support is not enough to motivate individuals with HIV / AIDS (Wagner 2009). A multi-factor approach is needed by individuals with HIV / AIDS who experience chronic depression (Helene \& Ricardo, 2006).

Support obtained by participants in the form of emotional support is by enthusiasm or provide motivation and assistance. The family is the closest person and is responsible for all decisions in taking care for individuals with HIV / AIDS. The families that are most expected to accompany individuals with HIV / AIDS are the closest family member (husband, parents, grandmother, in-laws, and siblings). Friends of people with HIV / AIDS are people who really understand 
the problems faced by people who are in distress. They also really understand how to ease the burden by approaching themselves closer to God.

\section{CONCLUSION}

The study was conducted with the technique of in-depth interviews with six participants. The theme of psychosocial support from the closest person consists of 3 categories, namely psychological support from the family, support from fellow friends with HIV / AIDS and support in undergoing treatment. The results of the study are new insights that post-partum women with HIV / AIDS experience accumulation from the process of chronic HIV / AIDS disease. Support is needed from the people closest to the family and support from fellow friends with HIV / AIDS to prevent a phase of desperation that can lead to death in post-partum women with HIV / AIDS.

\section{REFERENCES}

Ameneh, et. Al. (2013). Social Support Network among People Living with HIV/AIDS in Iran. AIDS Research an Treatment.

Carvehaels, benicio, dan Barros. (2005). The impact of social support and sense of coherence on health-related quality of life among nursing home residentsA questionnaire survey in Bergen, Norway. Nursing Studies, 46(1), 66-76.

Close, K. L(2010). The psychosocial aspect of HIV: Children and adolescents in HIV curriculums for the health professional. Texas BIAPAI, 7-14.

Direktorat Pemberantasan Penyakit Menular dan Penyehatan Lingkungan Kementrian Kesehatan RI. (2011). Laporan perkembangan HIV AIDS triwulan IV tahun 2010. Jakarta Dirjen P2PL.

Friedman, Marlyn. (2004). Family Nursing. Theory and Practice. Alih Bahasa Ina Debora. EGC. Jakarta 
Helene, L., \& Ricardo, Z. (2006). Sociopolitical determinant of an AIDS prevention program: Mutiple actors and vertical relationship of control and influence. Policy, Politics 7 nursing practice, 7, 125.

Ikatan Perempuan Positif Indonesia. (2010). Laporan Tahunan Ikatan Perempuan Indonesia. Jakarta

Laura Nyblade, A. S., Ellen Weiss, and Asbhurn Kim. (2009). Combatting HIV stigma in Health Care Setting: What works? Journal of the Internasional AIDS Society, 12, 15.

UNAIDS. (2010). The risk of HIV transmission during breastfeeding a table of research finding. AIDSTAR One.

Pender, N. J., Murdaugh, C. L., \& Parson, M. A. (2001). Health Promotion in Nursing Practice. NJ: Prentice Hall.

Person, et al. (2009). Next-of-Kin's Perceptions of How Hospital Nursing Staff Support Family Presence Before, During, and After the Death of a Loved One. Med Scape Multispeciality

Wagner, A. C. (2009). HIV stigma, psychological distress, and social support and their relationship to fertility intentions amongst HIV positive (HIV +)women. Digital Commons. 2, 1-15.

World Health Organization. (2011). Global HIV/AIDS response epidemic update and health sector progress toward universal access. Geneva WHO 